\section{Malignant Melamona}

Sir,

A 48-year male reported with a complaint of brownish-black pigmented area over the hard palate. Patient did not have pain or burning sensation. He was mostly concerned with his aesthetic appearance. Initially, he noticed a small patch of dark black pigmented area four months back that has increased to present size. There was a rapid spread of the lesion which covered the entire palatal region. On clinical examination, the lesion, was dark-blackish to brownish in color with irregular borders that was well demarcated from the surrounding area. The lesion mostly involved the left to central part of the hard palate, extending anterioposterorly from middle third to junction of the hard and soft palates. The surface appeared wrinkled, granular with a round proliferative elevated area seen in mid-palate region (Figure 1). On palpation, the lesion was fibrotic, non-scrapable and non-tender. The regional lymph nodes were not palpable. Based on the clinical examination and tumor size (tumor $>2 \mathrm{~cm}$ but not $>4 \mathrm{~cm}$ ) with no involvement of lymph nodes, it was staged as T2, N0, $\mathrm{M} 0$ as per TNM staging.

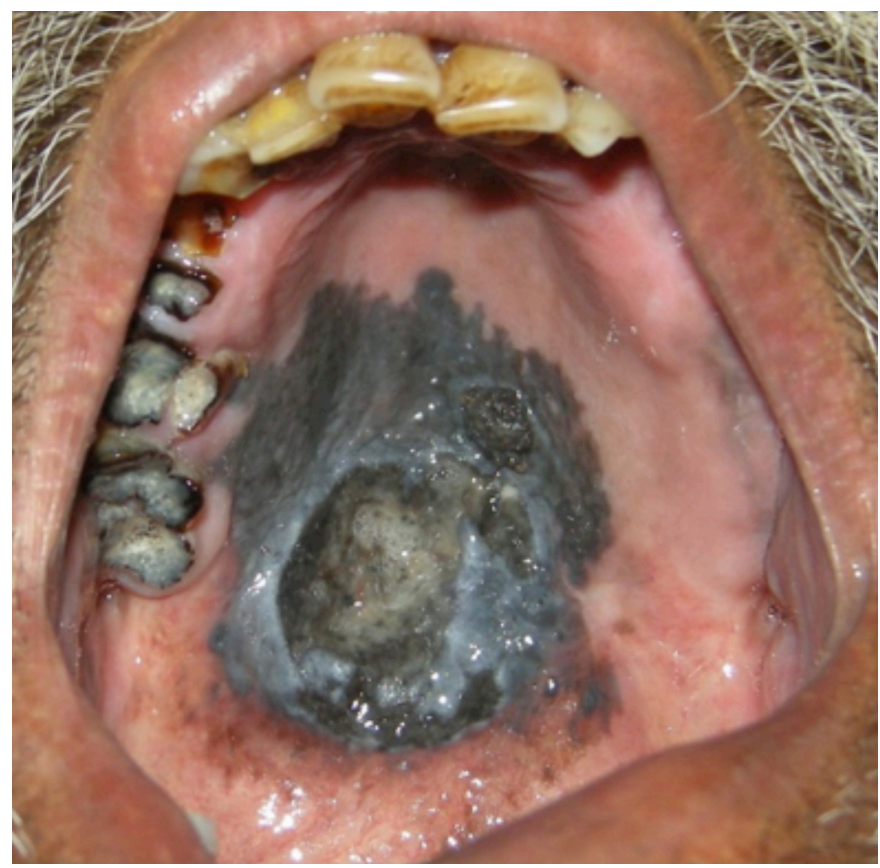

Figure 1: A well defined irregular shaped brownish black pigmented lesion over hard palate.

Under local anaesthesia, an excisional biopsy was done. Histopathological examination concluded malignant melanoma. In this case, since no nodal involvement and metastases were present, so surgery with extensive resection and reconstruction was considered as preferred option for treatment. He was referred to regional cancer institute, but did not report further.

Malignant melanoma is a skin cancer that originates from the melanocytes and is associated with an invasive growth pattern and rapid spread. ${ }^{1}$ Oral malignant melanomas are extremely rare lesions and comprise only $0.2-8 \%$ of all melanomas., ${ }^{2,3}$ Melanomas are clinically asymptomatic in the early stages and appear as hyperpigmented patches. Mucosal melanoma was first described by Weber in 1895. Tobacco smoking or chewing, denture irritation and formaldehyde exposure are suggested as causative agents for intraoral melanomas. Oral melanomas are mostly seen in 40 to 70 years age group, with male predominance. ${ }^{4}$ Most common site is the palate, followed by maxillary gingiva and other locations. ${ }^{5}$ The tumors tend to spread rapidly to other parts of the body causing death.

Surgery, chemotherapy, radiotherapy, and immunotherapy are treatment options. It has been shown that surgical excision, followed by immuno-chemotherapy, has reduced the recurrence of the lesion. The prognosis of oral melanoma is poor with five-year survival rate of $0-55 \%$.

Intraoral pigmented lesions are often ignored till they achieve large size, as they are mostly asymptomatic during early stages. An early and accurate diagnosis can be life-saving for the patient as they are usually very aggressive and can rapidly metastasise and cause death.

\section{PATIENT'S CONSENT:}

Informed consent was obtained from the patient to publish the data concerning this case.

\section{CONFLICT OF INTEREST:}

The authors declared no conflict of interest.

\section{AUTHORS' CONTRIBUTION:}

SS, SS: Contributed to the conception of the work, collected the patient data and images and participated in literature review and wrote the full manuscript..

\section{REFERENCES}

1. Lodde G, Zimmer L, Livingstone E, Schadendorf D, Ugurel S. Malignant melanoma. Hautarzt 2020; 71(1):63-77.

2. Boulaadas M, Benazzou S, Mourtada F. Primary oral malignant melanoma. J Craniofac Surg 2007; 18(5): 1059-61. doi: 10.1097/scs.0b013e3180f6120e.

3. Ebenezer J. Malignant melanoma of the oral cavity. Indian J Dent Res 2006; 17:94-6. doi: 10.4103/0970-9290.29882.

4. O'Neill CH, Scoggins. CR. Melanoma. J Surg Oncol 2019; 120(5):873-81. doi: 10.1002/jso.25604.

5. Lugović-Mihić L, Ćesić D, Vuković P, Novak Bilić G, Šitum M, Špoljar S. Melanoma Development: Current Knowledge on Melanoma Pathogenesis. Acta Dermatovenerol Croat 2019; 27(3):163-8.

Suman Sen ${ }^{1}$ and Sheuli Sen ${ }^{2}$

${ }^{1}$ Department of Oral Medicine and Radiology, Haldia Institute of Dental Sciences, India

${ }^{2}$ Department of Pediatric Nursing, Amity College of Nursing, India 
Correspondence to: Dr. Suman Sen, Department of Oral Medicine and Radiology, Haldia Institute of Dental Sciences, India

E-mail: dentalclinicip@gmail.com
Received: June 13, 2020; Revised: August 17, 2020; Accepted: August 18, 2020

DOI: https://doi.org/10.29271/jcpsp.2021.05.612

$\bullet \bullet \bullet \bullet \bullet \bullet \bullet \bullet \bullet$ 